\title{
molecules
}

ISSN 1420-3049

www.mdpi.com/journal/molecules

Article

\section{Optimization of Process Parameters of Extraction of Amentoflavone, Quercetin and Ginkgetin from Taxus chinensis Using Supercritical $\mathrm{CO}_{2}$ Plus Co-Solvent}

\author{
Xiao Ruan, Liu-Ye Yan, Xian-Xian Li, Ben Liu, Huan Zhang and Qiang Wang * \\ Ningbo Institute of Technology, Zhejiang University, Ningbo, 315100, China; \\ E-Mails: ruanxiao@nit.zju.edu.cn (X.R.); yanliuye@163.com (L.-Y.Y.); \\ lixianxian@163.com (X.-X.L.); liuben@nit.zju.edu.cn (B.L.); zhhuan@nit.zju.edu.cn (H.Z.) \\ * Author to whom correspondence should be addressed; E-Mail: wangqiangsky@263.net; \\ Tel.: +86-574-8813-4338; Fax: +86-574-8822-9545.
}

External Editor: Derek J. McPhee

Received: 10 September 2014; in revised form: 28 September 2014 / Accepted: 29 September 2014/ Published: 31 October 2014

\begin{abstract}
The effects of extraction time, temperature, pressure and different concentration of ethanol and their interactions on the yields of amentoflavone, quercetin and ginkgetin extracted from Taxus chinensis by supercritical $\mathrm{CO}_{2}$ were investigated by using a central composite design (CCD). An CCD experimental design with four factors and five levels was used to optimize the extraction parameters. Ultra performance liquid chromatography (UPLC) was used to analyze the content of the tree components in the extracts. Experimental results show that the main effects of factors and their interactions are significant on the yields $(p<0.05)$. The optimal extraction conditions were established for the three compounds: yield of $4.47 \mathrm{mg} / \mathrm{g}$ for amentoflavone at $48{ }^{\circ} \mathrm{C}, 25 \mathrm{MPa}, 2.02 \mathrm{~h}$ and $78.5 \%$ ethanol, $3.73 \mathrm{mg} / \mathrm{g}$ for quercetin at $46{ }^{\circ} \mathrm{C}, 24 \mathrm{MPa}, 2.3 \mathrm{~h}, 82 \%$ ethanol and $3.47 \mathrm{mg} / \mathrm{g}$ for ginkgetin at $48{ }^{\circ} \mathrm{C}, 20 \mathrm{MPa}, 2.38 \mathrm{~h}, 82 \%$ ethanol, respectively.
\end{abstract}

Keywords: supercritical fluid extraction; central composite design; flavonoids; Taxus chinensis 


\section{Introduction}

The flavonoids are one of the largest known groups of natural products, which are widely distributed in various plants [1,2]. One of the main interests in the pharmaceutical industry is that the compounds possess many biological activities such as scavenging of free radicals, immune modulation and hormone action and that they can serve as a starting point for the development of optimal derivatives [3-6]. Taxus is an important natural resource for the extraction of taxoids, which have been utilized as anticancer agents [7]. The increasing need of taxoids has leds to increasing amount of the extracts free of taxoids from Taxus [8]. It was later found that high contents of flavonoids exist in Taxus, which is significant to extract the flavonoids for food and pharmaceutical applications [9].

Supercritical $\mathrm{CO}_{2}$ extraction is currently regarded as a natural and green technique for natural product extraction, and an important alternative to conventional separation methods, not only because it is simpler, faster, and more efficient, but also because it does not require the consumption of large amounts of organic solvents which are both expensive and potentially harmful. The technique has been applied to extract bioactive compounds from natural resources [10].

The aim of this study is to investigate the effects of extraction time, temperature, pressure and different concentration of ethanol in supercritical $\mathrm{CO}_{2}$ extraction on the yields of amentoflavone, quercetin and ginkgetin (Figure 1) by applying a central composite design method. The method is a collection of statistical and mathematical methods that are useful for developing, improving and optimizing a process. Its main advantage is the reduced number of experimental trials required to assess multiple parameters and their interactions [11,12]. To our best knowledge, Taxus flavonoids from Taxus chinensis were extracted by SFE and analyzed with UPLC for the first time in this study.

Figure 1. Structures of Amentoflavone, Quercetin and Ginkgetin.

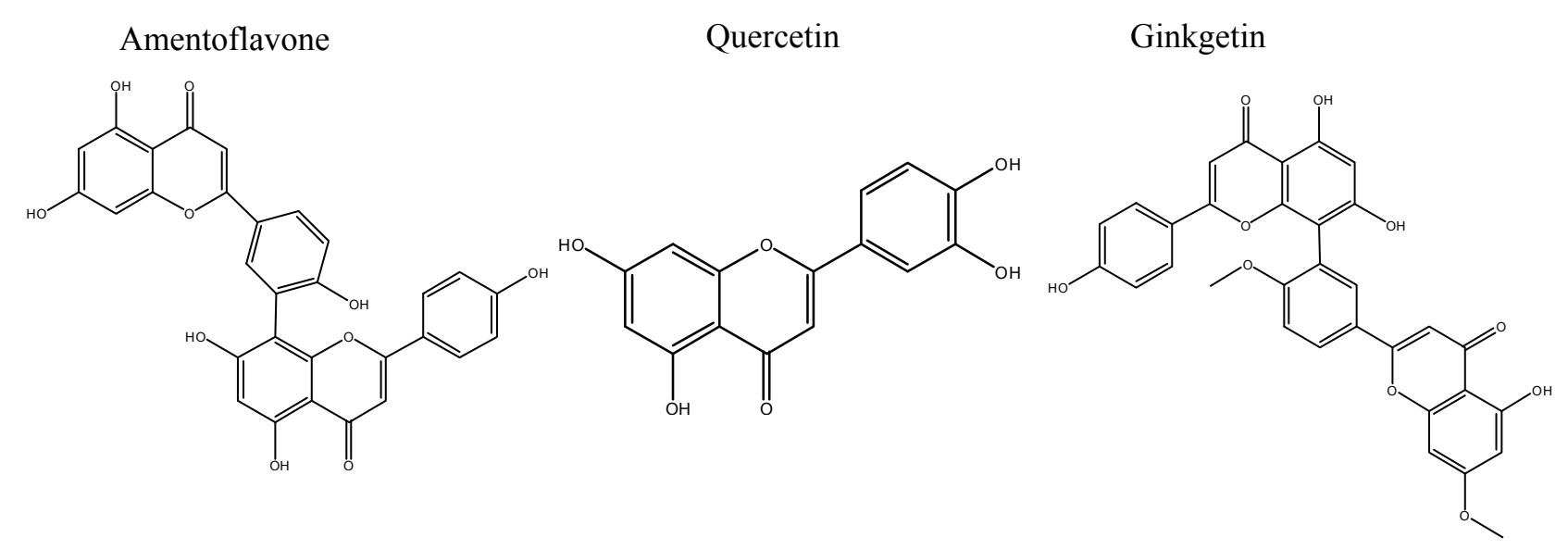

\section{Results and Discussion}

\subsection{UPLC Chromatogram}

The UPLC profile of a SFE extract of the powdered leaves of T. chinensis is seen in Figure 2. Based on the available standards of quercetin, amentoflavone and ginkgetin, it is possible to identify the corresponding peaks, which appear at retention times of approximately $7.16 \mathrm{~min}, 7.92 \mathrm{~min}$ and 
9.15 min, respectively. The extracts obtained by using SFE under different conditions show chromatograms similar to Figure 2.

Figure 2. Ultra performance liquid chromatogram of extract obtained with $\mathrm{CO}_{2}$ plus ethanol. 1. Quercetin; 2. Amentoflavone and 3. Ginkgetin.

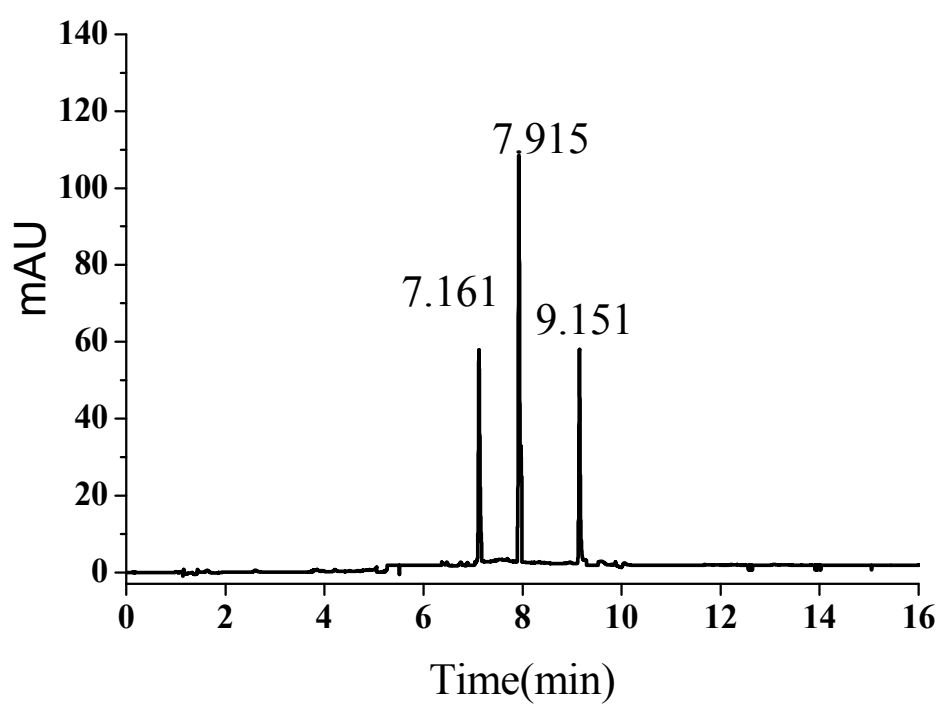

\subsection{Selection of Extraction Time}

Figure 3 displays the effect of extraction time on the yields of amentoflavone, quercetin and ginkgetin. It is possible to extract $>95 \%$ of them within $3 \mathrm{~h}$ (all yields being based on the recovery obtained after $4 \mathrm{~h}$ ), therefore an extraction time $<3 \mathrm{~h}$ was selected in this study. It can be observed that fast extraction of the flavonoids occurs within $2 \mathrm{~h}$.

Figure 3. The effect of extraction time on the yields of amentoflavone, quercetin and ginkgetin at temperature $50{ }^{\circ} \mathrm{C}$, pressure $20 \mathrm{MPa}$ and $\mathrm{CO}_{2}+75 \%$ ethanol.

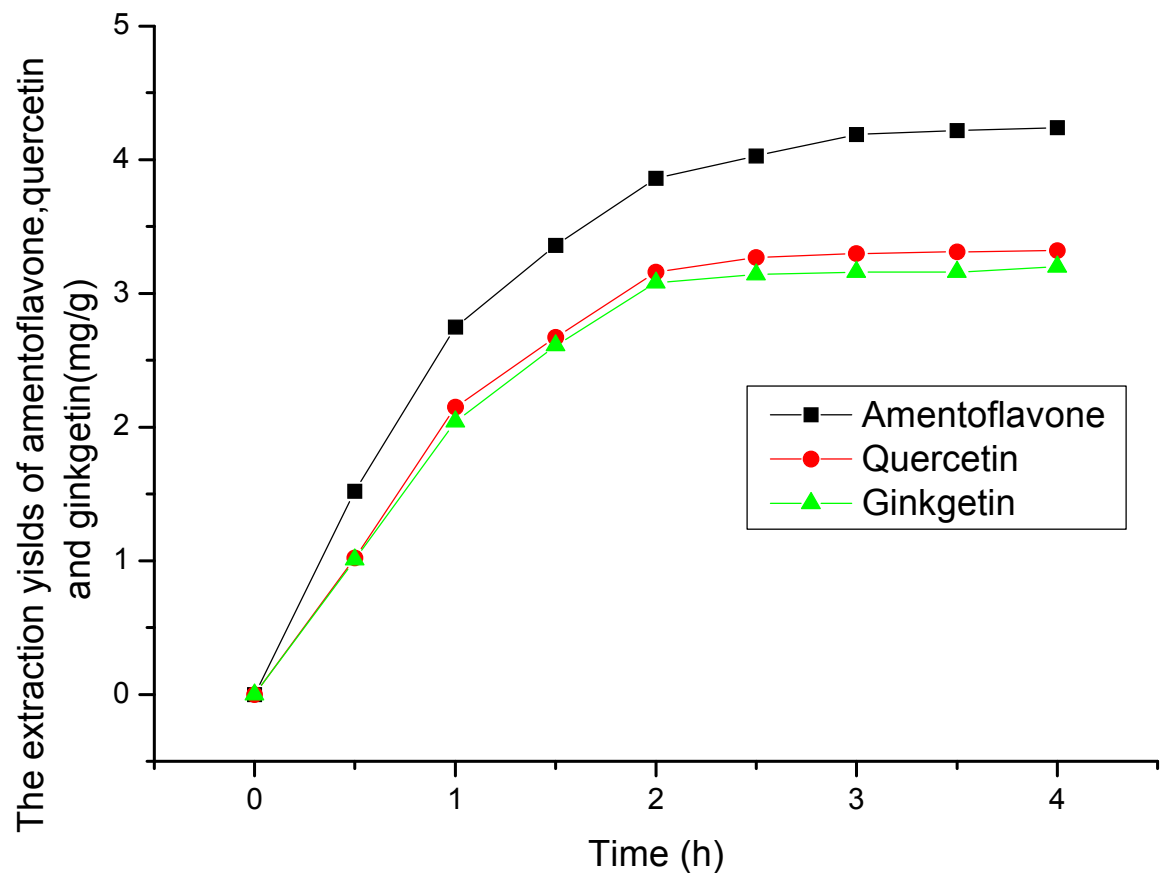




\subsection{Model Fitting and Evaluation of the Factors}

The main objective of this study was to investigate the process parameters for maximum extraction of amentoflavone, quercetin and ginkgetin from $T$. chinensis using SFE. The experimental design and values of independent variables are shown in Table 1. As analyzed using ANOVA (Table 2), the models were highly significant with very low $p$-values $(p<0.0001)$ with $\mathrm{R}^{2}$ value $0.9892,0.9832$, and 0.9849 , respectively, for the extraction of the components. These values indicated that the polynomial regression models were suitable to determine optimum conditions for the extraction of the three components. As seen from Table 2, the $p$-values of the four main variables are less than 0.05 . Therefore, extraction time, temperature, pressure and ethanol concentration have significant effects on the yields of the three components. Interactions of time $\times$ pressure $\left(\mathrm{X}_{1} \mathrm{X}_{3}\right)$ and pressure $\times$ ethanol concentration $\left(\mathrm{X}_{3} \mathrm{X}_{4}\right)$ are significant $(p<0.05)$ while the other interactions are insignificant in the model for the extraction of amentoflavone. Interaction of pressure $\times$ ethanol concentration $\left(\mathrm{X}_{3} \mathrm{X}_{4}\right)$ are significant for the extraction of quercetin. Interactions of time $\times$ ethanol concentration $\left(\mathrm{X}_{1} \mathrm{X}_{4}\right)$, temperature $\times$ pressure $\left(\mathrm{X}_{2} \mathrm{X}_{3}\right)$ and temperature $\times$ ethanol concentration $\left(\mathrm{X}_{2} \mathrm{X}_{4}\right)$ are significant for the extraction of ginkgetin.

Fitting a regression surface to the experimental results, the following Equations (1)-(3) were obtained, applicable to predict the achievable amentoflavone yield $\left(Y_{1}\right)$, quercetin yield $\left(Y_{2}\right)$ and ginkgetin yield $\left(Y_{3}\right)$, respectively as a function of the studied process variables:

$$
\begin{aligned}
& Y_{1}(\mathrm{mg} / \mathrm{g})=4.34+0.24 \mathrm{X}_{1}+0.09 \mathrm{X}_{2}+0.26 \mathrm{X}_{3}+0.04 \mathrm{X}_{4}-0.14 \mathrm{X}_{1}^{2}-0.058 \mathrm{X}_{2}^{2}- \\
& 0.14 \mathrm{X}_{3}^{2}-0.34 \mathrm{X}_{4}^{2}-5.63 \times 10^{-} 3 \mathrm{X}_{1}-0.043 \mathrm{X}_{1} \mathrm{X}_{3}-0.021 \mathrm{X}_{1} \mathrm{X}_{4}+0.033 \mathrm{X}_{2} \mathrm{X}_{3}- \\
& 0.017 \mathrm{X}_{2} \mathrm{X}_{4}-0.047 \mathrm{X}_{3} \mathrm{X}_{4} \\
& Y_{2}(\mathrm{mg} / \mathrm{g})=3.54+0.16 \mathrm{X}_{1}+0.094 \mathrm{X}_{2}+0.19 \mathrm{X}_{3}-0.13 \mathrm{X}_{4}-0.059 \mathrm{X}_{1}^{2}-0.035 \mathrm{X}_{2}^{2}- \\
& 0.079 \mathrm{X}_{3}^{2}-0.49 \mathrm{X}_{4}^{2}+0.018 \mathrm{X}_{1} \mathrm{X}_{2}+0.042 \mathrm{X}_{1} \mathrm{X}_{3}+6.25 \times 10^{-4} \mathrm{X}_{1} \mathrm{X} 4-0.046 \mathrm{X}_{2} \mathrm{X}_{3}+ \\
& 0.051 \mathrm{X}_{2} \mathrm{X}_{4}+0.18 \mathrm{X}_{3} \mathrm{X}_{4} \\
& Y_{3}(\mathrm{mg} / \mathrm{g})=3.27+0.13 \mathrm{X}_{1}+0.16 \mathrm{X}_{2}+0.15 \mathrm{X}_{3}+0.083 \mathrm{X}_{4}-0.076 \mathrm{X}_{1}^{2}-0.12 \mathrm{X}_{2}^{2}- \\
& 0.12 \mathrm{X}_{3}^{2}-0.55 \mathrm{X}_{4}^{2}+0.048 \mathrm{X}_{1} \mathrm{X}_{2}+0.016 \mathrm{X}_{1} \mathrm{X}_{3}+0.078 \mathrm{X}_{1} \mathrm{X}_{4}+0.097 \mathrm{X}_{2} \mathrm{X}_{3}- \\
& 0.061 \mathrm{X}_{2} \mathrm{X}_{4}-0.066 \mathrm{X}_{3} \mathrm{X}_{4}
\end{aligned}
$$

A positive sign indicates a synergistic effect while negative sign represents an antagonistic effect of the factor on the response of the model. Therefore, the main effects of extraction time, temperature, pressure and ethanol concentration have positive effects on amentoflavone and ginkgetin yield. Extraction time, temperature and pressure have positive effects, while the main effect of ethanol concentration plays a negative role on quercetin yield. 
Table 1. Experimental design using central composite design with corresponding experimental results.

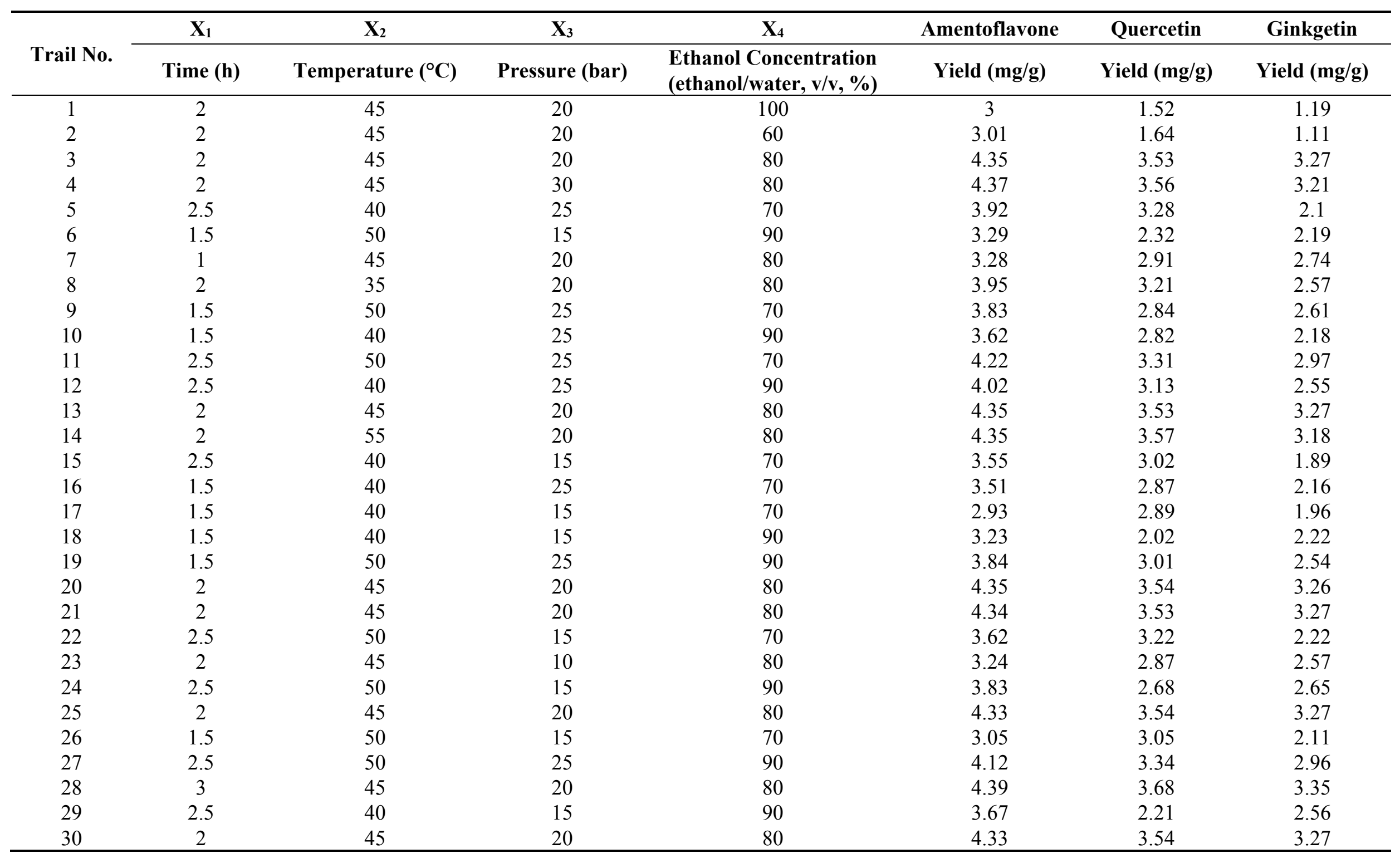


Table 2. ANOVA analysis of four parameters for SFE.

\begin{tabular}{|c|c|c|c|c|c|c|c|c|c|c|c|c|}
\hline \multirow{2}{*}{ Source } & \multicolumn{4}{|c|}{ Amentoflavone } & \multicolumn{4}{|c|}{ Quercetin } & \multicolumn{4}{|c|}{ Ginkgetin } \\
\hline & Sum of Squares & F-value & $p$-value & $\mathbf{R}^{2}$ & Sum of Squares & F-value & $p$-value & $\mathbf{R}^{2}$ & Sum of Squares & F-value & $p$-value & $\mathbf{R}^{2}$ \\
\hline Model & 7.01 & 98.42 & $<0.0001$ & 0.9892 & 9.36 & 62.56 & $<0.0001$ & 0.9832 & 10.51 & 69.83 & $<0.0001$ & 0.9849 \\
\hline $\mathrm{X}_{1}$ & 1.44 & 282.28 & $<0.0001$ & & 0.64 & 59.6 & $<0.0001$ & & 0.41 & 38.44 & $<0.0001$ & \\
\hline $\mathrm{X}_{3}$ & 1.59 & 311.87 & $<0.0001$ & & 0.87 & 81.42 & $<0.0001$ & & 0.53 & 48.82 & $<0.0001$ & \\
\hline $\mathrm{X}_{4}$ & 0.039 & 7.71 & 0.0141 & & 0.42 & 39.67 & $<0.0001$ & & 0.16 & 15.34 & 0.0014 & \\
\hline $\mathrm{X}_{1} \mathrm{X}_{2}$ & 0.000506 & 0.1 & 0.7567 & & 0.0053 & 0.49 & 0.4939 & & 0.037 & 3.44 & 0.0832 & \\
\hline $\mathrm{X}_{1} \mathrm{X}_{4}$ & 0.0068 & 1.34 & 0.2654 & & $6.3 \mathrm{E}-06$ & 0.00058 & 0.9810 & & 0.098 & 9.08 & 0.0087 & \\
\hline $\mathrm{X}_{2} \mathrm{X}_{3}$ & 0.018 & 3.45 & 0.0829 & & 0.033 & 3.12 & 0.0979 & & 0.15 & 13.96 & 0.0020 & \\
\hline $\mathrm{X}_{2} \mathrm{X}_{4}$ & 0.0045 & 0.9 & 0.3589 & & 0.041 & 3.84 & 0.0690 & & 0.059 & 5.47 & 0.0336 & \\
\hline $\mathrm{X}_{3} \mathrm{X}_{4}$ & 0.035 & 6.91 & 0.0190 & & 0.54 & 50.89 & $<0.0001$ & & 0.069 & 6.41 & 0.0230 & \\
\hline $\mathrm{X}_{1}^{2}$ & 0.51 & 100.27 & $<0.0001$ & & 0.096 & 8.95 & 0.0091 & & 0.16 & 14.87 & 0.0016 & \\
\hline $\mathrm{X}_{2}^{2}$ & 0.091 & 17.89 & 0.0007 & & 0.034 & 3.2 & 0.0938 & & 0.39 & 36.02 & $<0.0001$ & \\
\hline
\end{tabular}


A correlation graph shows that a high correlation exists between the experimental and predicted values (see Figure 4). Each point is close to the regression line, which indicates the good fit of the model. Based on Equations (2)-(4), the optimal extraction conditions are $48{ }^{\circ} \mathrm{C}, 25 \mathrm{MPa}, 2.02 \mathrm{~h}$ and $78.5 \%$ ethanol with the yield of $4.47 \mathrm{mg} / \mathrm{g}$ for amentoflavone extraction; $46{ }^{\circ} \mathrm{C}, 24 \mathrm{MPa}, 2.3 \mathrm{~h}, 82 \%$ ethanol with the yield of $3.73 \mathrm{mg} / \mathrm{g}$ for quercetin and $48{ }^{\circ} \mathrm{C}, 20 \mathrm{MPa}, 2.38 \mathrm{~h}, 82 \%$ ethanol with the yield of $3.47 \mathrm{mg} / \mathrm{g}$ for ginkgetin.

Figure 4. Correlation graph between the predicted and experimental yield values.
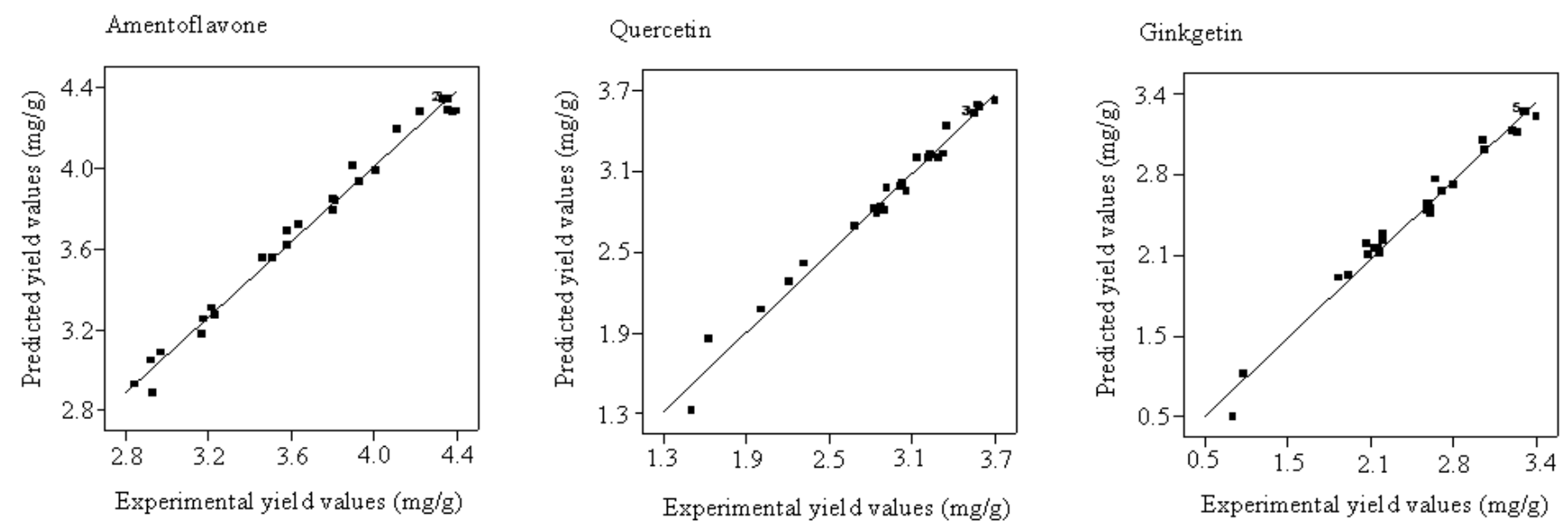

3D response surface curves can be used to provide a better understanding of interaction between any two factors. Response surface plots are generally the graphical representation of the regression equation. In the present study, each response surface presents the effect of any two factors on the wear loss while other two factors are held at the middle level. Figure 5a shows the interaction effect of time and temperature on amentoflavone yield while pressure and ethanol concentration are kept constant at values of $20 \mathrm{MPa}$ and $80 \%$ (ethanol: water, $\mathrm{v} / \mathrm{v}$ ), respectively. This response surface plot indicates that longer extraction times and higher temperatures favor amentoflavone extraction. The maximum yield $(4.48 \mathrm{mg} / \mathrm{g})$ was obtained at extraction times longer than $2.35 \mathrm{~h}$ and temperatures above $48{ }^{\circ} \mathrm{C}$. A longer extraction time was helpful for exhaustive extraction. Temperature can affect the extraction. The $\mathrm{CO}_{2}$ solvation power depends on solvent density, which decreases with temperature and increases with pressure. The phenomenon of increase in the yield with raising extraction temperature could be due to the enhancement in the solute (amentoflavone) vapor pressure with higher temperature, which was more significant than the reduction in the solvent density, increasing consequently the extraction temperature [13]. Similar effects of time and temperature on quercetin and ginkgetin yield can also be observed in Figures $6 \mathrm{a}$ and 7a, respectively. Higher quercetin and ginkgetin yields occurred when the extraction time was longer and the extraction was performed at higher temperature. However, the interaction between time and temperature was not statistically significant $(p>0.05)$.

The effect of different combinations of extraction time and pressure on amentoflavone, quercetin and ginkgetin yield is shown in Figures $5 \mathrm{~b}, 6 \mathrm{~b}$ and $7 \mathrm{~b}$, respectively, while temperature and ethanol concentration are kept constant at values of $45^{\circ} \mathrm{C}$ and $80 \%(\mathrm{v} / \mathrm{v})$, respectively. It was observed from Figure $5 \mathrm{~b}$ that higher yields (higher than $4.5 \mathrm{mg} / \mathrm{g}, 2.3 \mathrm{mg} / \mathrm{g}$ and $3.3 \mathrm{mg} / \mathrm{g}$ for amentoflavone, quercetin and ginkgetin, respectively) were attained by setting the extraction time at longer than $2 \mathrm{~h}$ and the pressure higher than $22 \mathrm{MPa}$. 
Figure 5. Response surface and contour plots of amentoflavone showing (a) the effect of time and temperature at constant $20 \mathrm{MPa}$ and $80 \%$ ethanol, (b) the effect of time and pressure at constant $45{ }^{\circ} \mathrm{C}$ and $80 \%$ ethanol, (c) the effect of time and ethanol concentration at constant $45{ }^{\circ} \mathrm{C}$ and $20 \mathrm{MPa},(\mathbf{d})$ the effect of temperature and pressure at constant $2 \mathrm{~h}$ extraction and $80 \%$ ethanol, (e) the effect of temperature and ethanol concentration at constant $2 \mathrm{~h}$ extraction and $20 \mathrm{MPa}$ and (f) the effect of pressure and ethanol concentration at constant $2 \mathrm{~h}$ extraction and $45^{\circ} \mathrm{C}$.

(a)

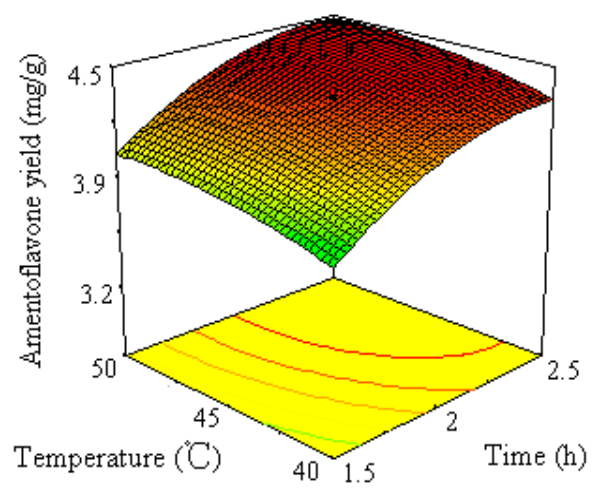

(c)

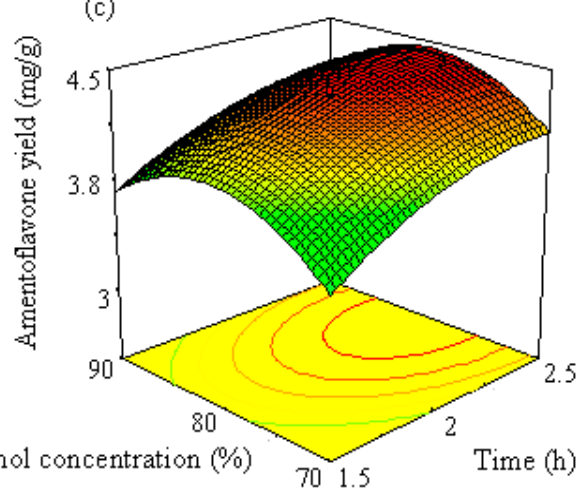

(e)

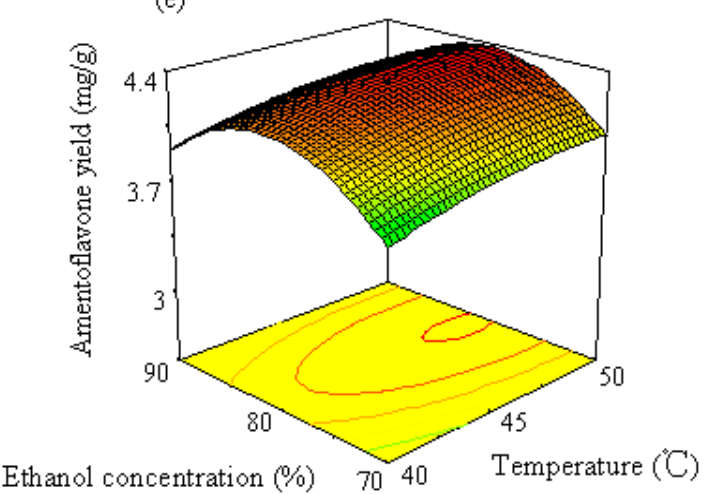

(b)

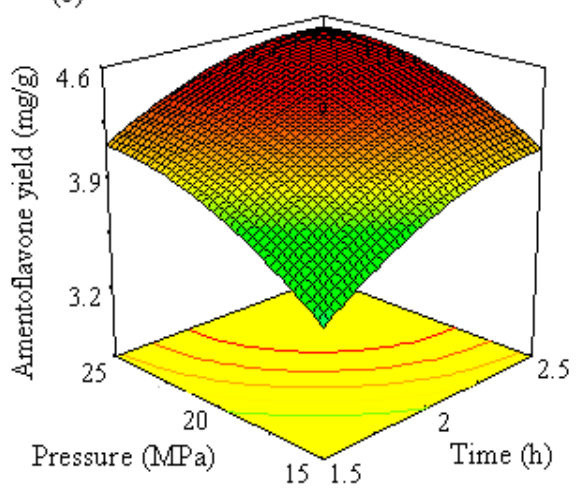

(d)

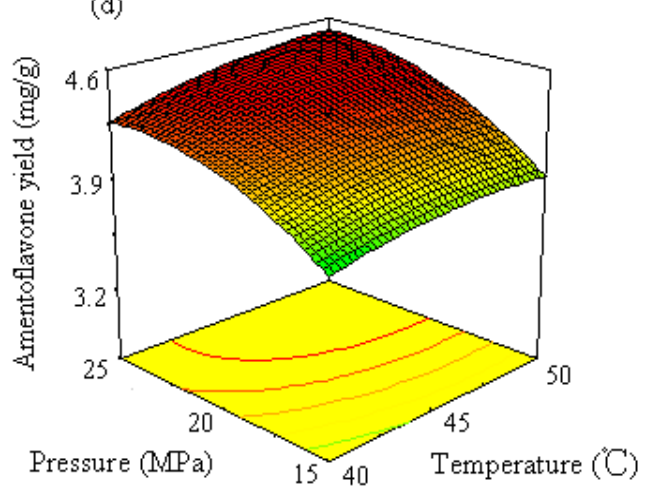

(f)

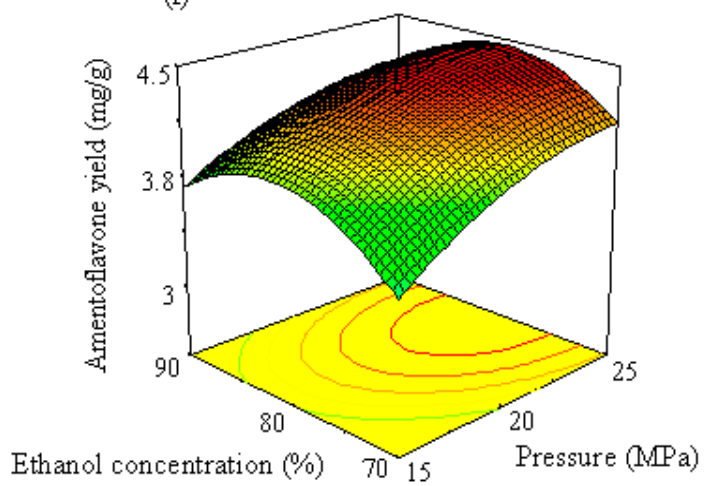

The pressure increase, at constant temperature, enhances the extraction yield due to the increased $\mathrm{CO}_{2}$ density and consequently in the solvating power. The interaction between extraction time and pressure was significant $(p<0.05)$ for amentoflavone extraction, while the interaction was not significant for quercetin and ginkgetin extraction. 
Figure 6. Response surface and contour plots of quercetin showing (a) the effect of time and temperature at constant $20 \mathrm{MPa}$ and $80 \%$ ethanol, (b) the effect of time and pressure at constant $45{ }^{\circ} \mathrm{C}$ and $80 \%$ ethanol, (c) the effect of time and ethanol concentration at constant $45{ }^{\circ} \mathrm{C}$ and $20 \mathrm{MPa}$, (d) the effect of temperature and pressure at constant $2 \mathrm{~h}$ extraction and $80 \%$ ethanol, (e) the effect of temperature and ethanol concentration at constant $2 \mathrm{~h}$ extraction and $20 \mathrm{MPa}$ and (f) the effect of pressure and ethanol concentration at constant $2 \mathrm{~h}$ extraction and $45^{\circ} \mathrm{C}$.

(a)

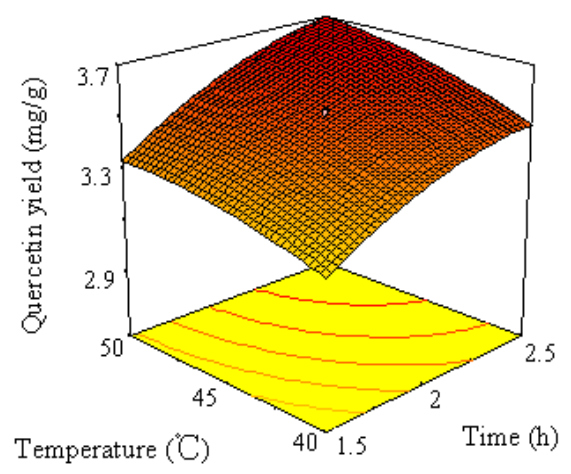

(c)

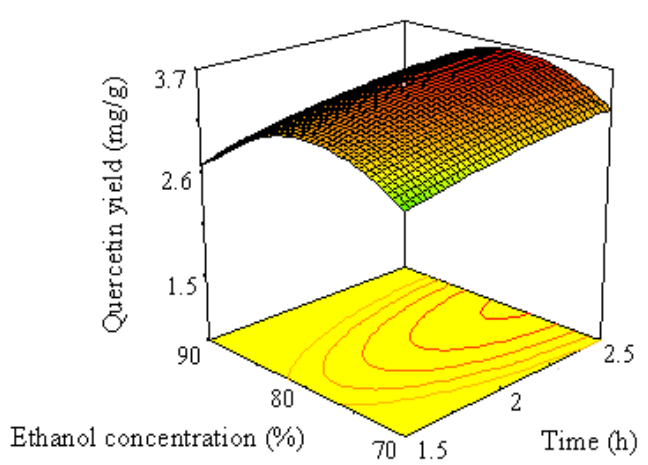

(e)

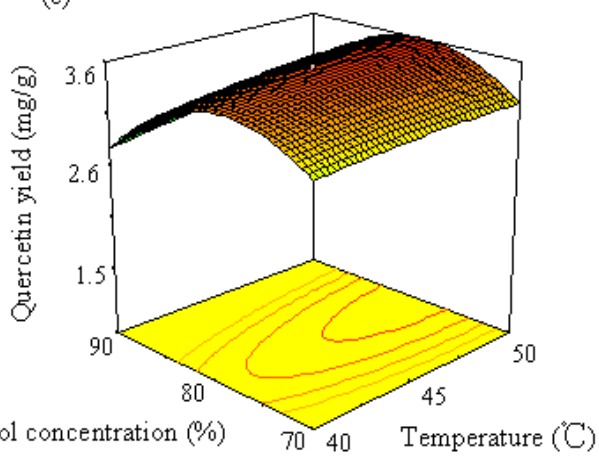

(b)

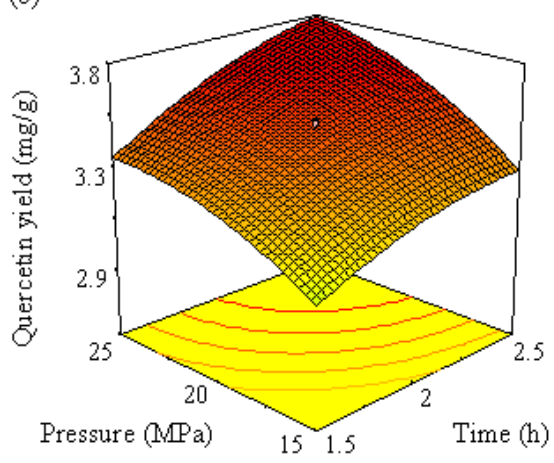

(d)

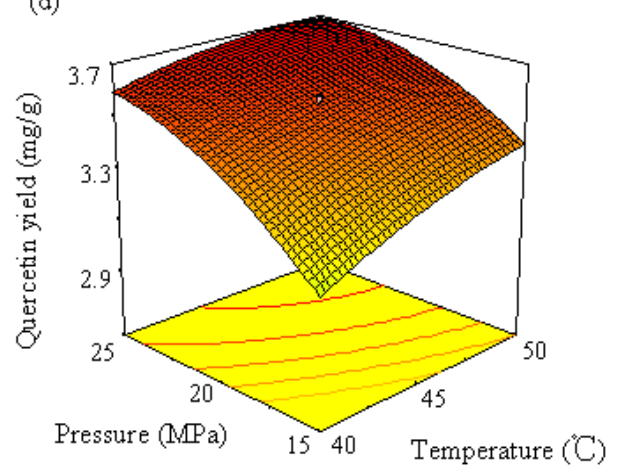

(f)

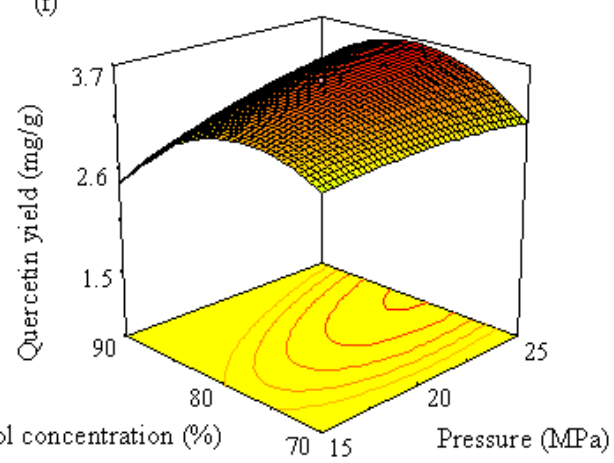

Figures $5 \mathrm{c}, 6 \mathrm{c}$ and $7 \mathrm{c}$ illustrate the effect of extraction time and ethanol concentration on amentoflavone, quercetin and ginkgetin yield. The yield of amentoflavone was obviously affected by ethanol concentration. It was not suitable to use lower or higher concentration of ethanol for extraction of amentoflavone. The change of extraction yield with ethanol concentration could be explained by the fact of a similar polar solvent dissolving a similar polar solute. Higher yields can be attained when the polarity of the fluid matches the polarity of the compound to be extracted. Higher yields $(>4.4 \%)$ of 
amentoflavone were obtained when thee ethanol concentration was in the $75 \%$ to $84 \%$ range and the extraction time was from $2.1 \mathrm{~h}$ to $2.5 \mathrm{~h}$. Similar effects of ethanol concentration on quercetin and ginkgetin yield were observed. Higher yield $(3.5 \mathrm{mg} / \mathrm{g}$ or $3.2 \mathrm{mg} / \mathrm{g})$ was produced when the ethanol concentration was in the $74 \%$ to $83 \%$ range or in the $77 \%$ to $84 \%$ range for quercetin and ginkgetin, respectively. The interaction between time and ethanol concentration was statistically significant for ginkgetin extraction.

Figure 7. Response surface and contour plots of ginkgetin showing (a) the effect of time and temperature at constant $20 \mathrm{MPa}$ and $80 \%$ ethanol, (b) the effect of time and pressure at constant $45{ }^{\circ} \mathrm{C}$ and $80 \%$ ethanol, (c) the effect of time and ethanol concentration at constant $45{ }^{\circ} \mathrm{C}$ and $20 \mathrm{MPa}$, (d) the effect of temperature and pressure at constant $2 \mathrm{~h}$ extraction and $80 \%$ ethanol, (e) the effect of temperature and ethanol concentration at constant $2 \mathrm{~h}$ extraction and $20 \mathrm{MPa}$, and (f) the effect of pressure and ethanol concentration at constant $2 \mathrm{~h}$ extraction and $45^{\circ} \mathrm{C}$.

(a)

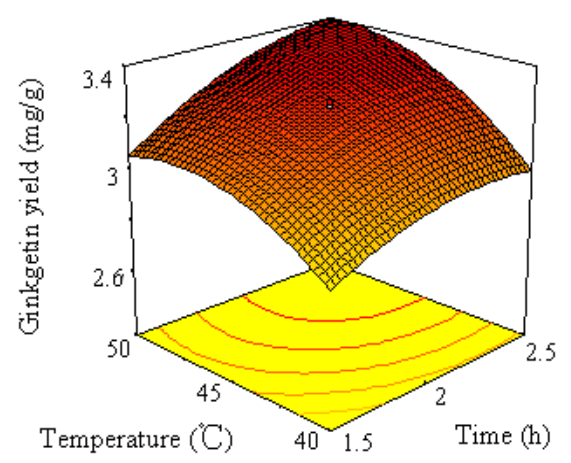

(c)

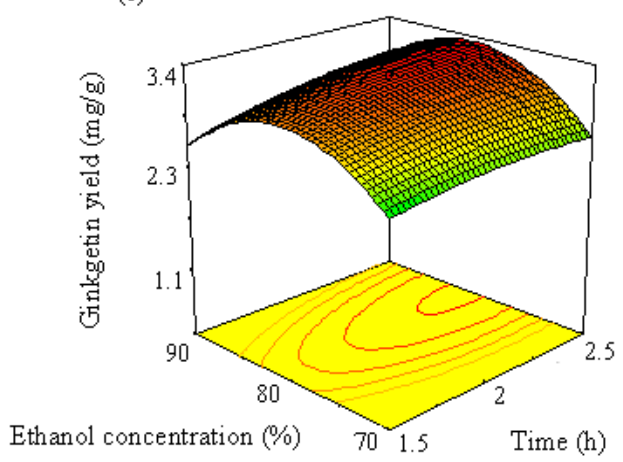

(e)

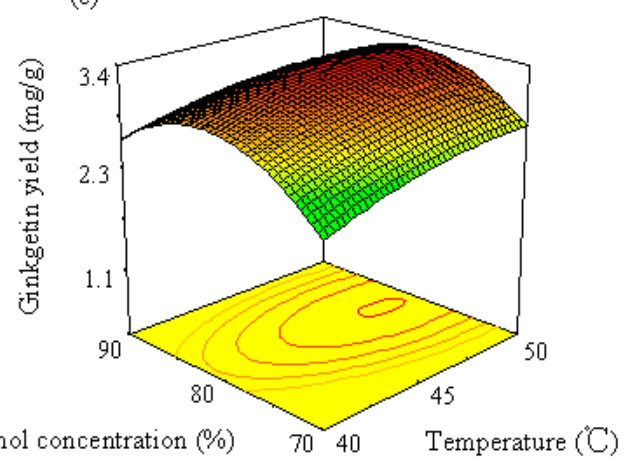

(b)

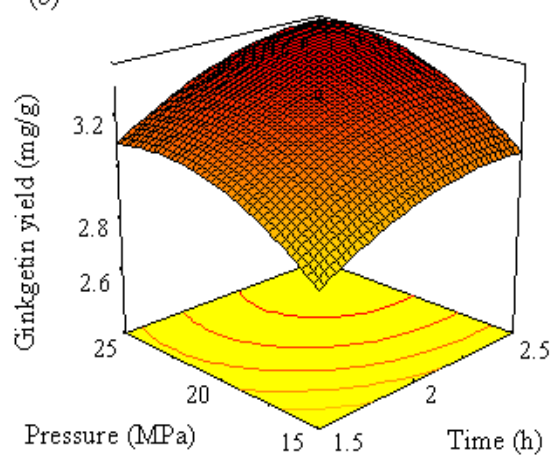

(d)

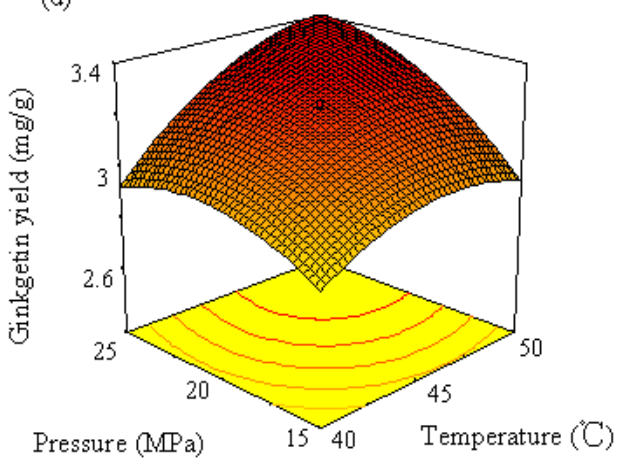

(f)

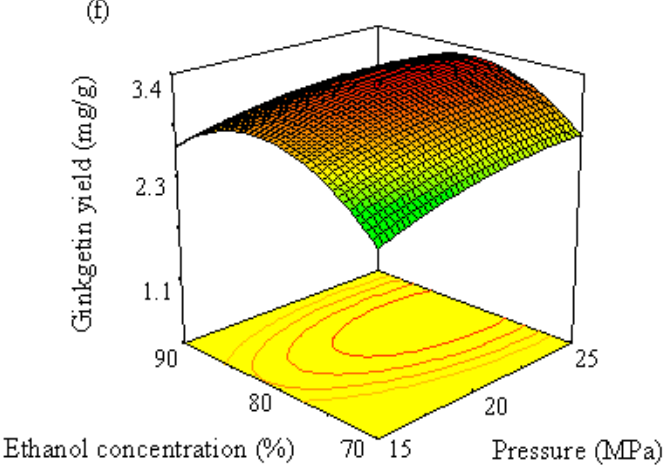


When considering the effects of temperature and pressure on the yields of amentoflavone, quercetin and ginkgetin, higher yields were attained at higher temperature and higher pressure as shown in Figures $5 \mathrm{~d}, 6 \mathrm{~d}$ and $7 \mathrm{~d}$. Higher yields occurred in the 45 to $50{ }^{\circ} \mathrm{C}$ temperature range and a pressure of 20 to $25 \mathrm{MPa}$ for the extraction of the three components. The yield improvement could be the result of rising vapor pressure at higher temperature and increasing fluid density with elevated pressure [14]. The interaction between temperature and pressure was statistically significant for ginkgetin extraction.

Response surface plots in Figures 5e, 6e and 7e show the effects of temperature and ethanol concentration on the yields of amentoflavone, quercetin and ginkgetin, respectively. It was observed that the amount of amentoflavone, quercetin and ginkgetin extracted could be influenced by ethanol concentration. When the ethanol concentration was increased from $45 \%$ to $81 \%$, the improvement of yields was from 4 to $4.3 \mathrm{mg} / \mathrm{g}$. As ethanol concentration increased further, amentoflavone yield decreased while extraction time and pressure were kept at the middle level, as displayed in Figure 5e. Higher yields $(>4.3 \mathrm{mg} / \mathrm{g})$ were obtained by setting temperature higher than $42{ }^{\circ} \mathrm{C}$ and ethanol concentration between $76 \%$ and $84 \%$. Similar effects of temperature and ethanol concentration on yields were observed for quercetin and ginkgetin.

The effects of pressure and ethanol concentration on the yields of amentoflavone, quercetin and ginkgetin are shown in Figures 5f, $6 f$ and $7 f$, respectively. It was observed from Figure $4 f$ that higher yields (higher than $4.3 \mathrm{mg} / \mathrm{g}$ ) for amentoflavone were attained when the extraction pressure was set higher than $19 \mathrm{MPa}$ and the ethanol concentration was between $74 \%$ and $85 \%$. Similar conditions could also be used for the extraction of quercetin and ginkgetin (Figures $6 \mathrm{f}$ and $7 \mathrm{f}$, respectively). Pressure and ethanol concentration have a significant interaction for the extraction of the three components $(p<0.05)$.

Table 3 shows that the suitability of the predictive value derived from the estimated models under the optimal extraction conditions (time $2 \mathrm{~h}$, temperature $48^{\circ} \mathrm{C}$, pressure $25 \mathrm{Mpa}$, ethanol concentration $78 \%$, flow-rate $2 \mathrm{~L} / \mathrm{min} \mathrm{CO}_{2}$ ) and experimental values for amentoflavone, quercetin and ginkgetin yields. Experimental values were not significantly different from the predicted values within the $95 \%$ confidence interval. Amentoflavone, quercetin and ginkgetin purity in the extracts is also compared in Table 3. The purity obtained with ethanol-modified supercritical $\mathrm{CO}_{2}$ was four times higher than that with Soxhlet extraction. Furthermore, the yield obtained with ethanol-modified supercritical $\mathrm{CO}_{2}$ was higher than that obtained with Soxhlet extraction. This reveals that an exhaustive extraction was obtained with ethanol as co-solvent in supercritical $\mathrm{CO}_{2}$ extraction under the selected operation conditions.

Table 3. Extraction yields and purity of amentoflavone, quercetin and ginkgetin from the leaves of T. chinensis.

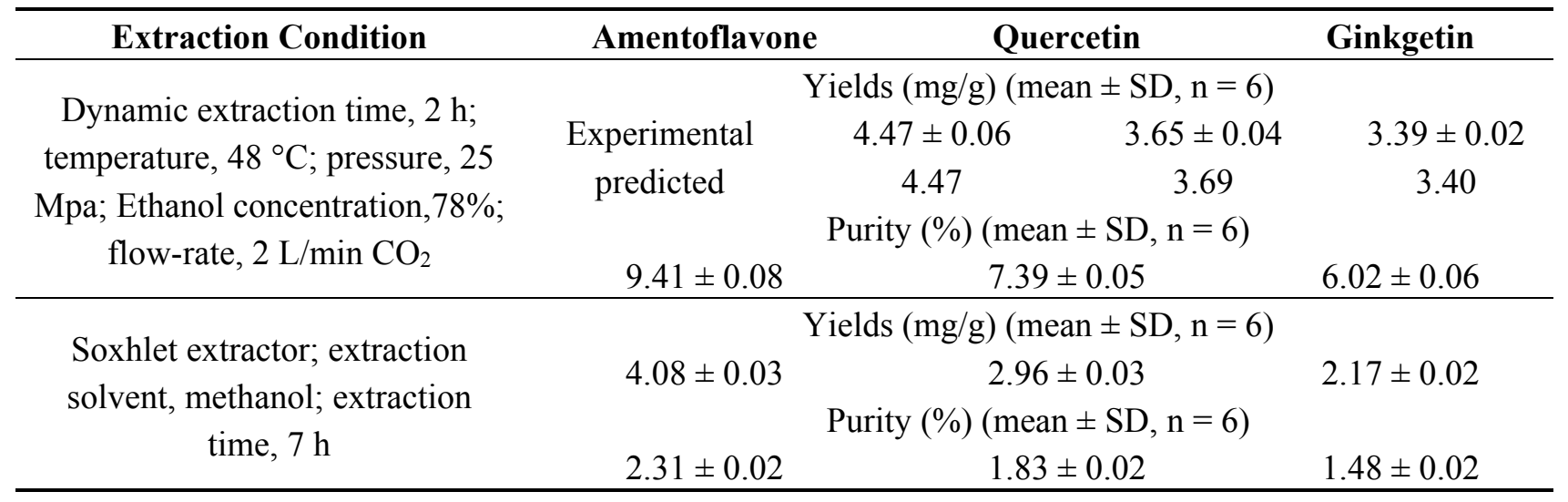




\section{Experimental Section}

\subsection{Materials and Reagents}

Leaves of $T$. chinensis were collected from five trees located at Ningbo Taxus Bio-engineering $\left(29^{\circ} 18^{\prime \prime} \mathrm{N} / 17^{\circ} 32^{\prime} \mathrm{E}\right.$, Ningbo, China) on 15-20 September 2012. The leaves were ground into powder using a herbal pulverizer (FW 100, Tianjin Taisite Instrument Co. Ltd, Tianjia, China) and sieved through a $250 \mu \mathrm{m}$ filter for extraction later. Quercetin, amentoflavone and ginkgetin standards were purchased from the National Institutes for Food and Drug Control (Beijing, China). $\mathrm{CO}_{2}$ (purity 99.5\%) was supplied by Fangxin Gas Ltd. (Ningbo, China). Acetonitrile of HPLC grade was from Tedia Chemicals (Charlotte, NC, USA). Ethanol and methanol (analytical grade) were purchased from Sinopharm Chemical Reagent Co. Ltd. (Shanghai, China). Celite (chemical grade) was from Fengcheng Chemical Ltd. (Shanghai, China).

\subsection{Supercritical Fluid Extraction}

A supercritical fluid extractor Spe-ed SFE-2 (Applied Separation, Franklin, PA, USA) was used, which operates with two pumps, a master pump for delivery of $\mathrm{CO}_{2}$ and a second pump (Knauer pump, model K-501, Berlin, Germany) for the addition of co-solvent. An accurately weighed quantity of grounded sample (about $1 \mathrm{~g}$ ) was placed in a $10 \mathrm{~mL}$ extraction vessel $(60 \times 15 \mathrm{~mm}$, i.d.) and the void volume was filled with Celite. Before the extraction was started, the extraction vessel was preheated in the oven for $10 \mathrm{~min}$. The extraction conditions were as follows: extraction time, static extraction for $5 \mathrm{~min}$ and then dynamic extraction up to $3 \mathrm{~h}$; temperature, from 35 to $55{ }^{\circ} \mathrm{C}$; pressure, from 10 to $30 \mathrm{MPa}$; Modifier ethanol concentration, $60 \%$ to $100 \%$ (ethanol/water, v/v); flow-rate of carbon dioxide (gaseous state), $2 \mathrm{~L} / \mathrm{min}$; flow-rate of modifier, $0.4 \mathrm{~mL} / \mathrm{min}$. Collection is at room temperature and atmospheric pressure. The extracts are collected in glass vials ( $30 \mathrm{~mL}$ containing $4 \mathrm{~mL}$ of methanol) with a rubber plug at the top. A metal extension to the metering valve is used to pierce the rubber plug and allow collection directly in the collection solvent. A hypodermic needle is pierced through the plug and connected to a flow meter. The extracts were quantitatively transferred to a $25 \mathrm{~mL}$ volumetric flask and made up to the mark with methanol. This solution was analyzed with UPLC.

\subsection{Soxhlet Extraction}

A known quantity of ground sample $(2.0 \mathrm{~g})$ was accurately weighed into a thimble and was extracted in a $50 \mathrm{~mL}$ extractor with $50 \mathrm{~mL}$ of methanol at a syphon rate of 1 cycle/ $15 \mathrm{~min}$. After $7 \mathrm{~h}$ of extraction with the solvent, the extraction solvent was essentially colorless and the extracts were transferred to a $50 \mathrm{~mL}$ volumetric flask and made up to the mark with methanol. This solution was analyzed. All extracts were filtered through a $0.22 \mu \mathrm{m}$ membrane filter before injecting into the UPLC system.

\subsection{UPLC Analysis}

Chromatography was performed using a UPLC system module 1290 infinity (Agilent, Santa Clara, CA, USA) equipped with photodiode array detector. ZORBAX Eclipse C18 column $(2.1 \times 150 \mathrm{~mm}$, $1.8 \mu \mathrm{m}$ particle size, Santa Clara, CA, USA) was used for separation and the column temperature was 
maintained at $30{ }^{\circ} \mathrm{C}$. Detection was at a wavelength of $360 \mathrm{~nm}$. Elution with solvent A (water) and solvent B (100\% acetonitrile) in a step gradient manner at a flow rate of $0.3 \mathrm{~mL} / \mathrm{min}$ was carried out as follows: $0-1 \mathrm{~min}, 10 \% \mathrm{~B}$; $1-3 \mathrm{~min}, 10 \%-20 \% \mathrm{~B}$; 3-6 $\mathrm{min}, 20 \%-45 \% \mathrm{~B}$; $6-8 \mathrm{~min}, 45 \%-75 \% \mathrm{~B}$; $8-15 \mathrm{~min}, 75 \% \mathrm{~B}$; the sample injection volume was $1 \mu \mathrm{L}$. A series of standards $(\mathrm{n}=6)$ in the range of 20-200 $\mu \mathrm{g} / \mathrm{mL}, 63-630 \mu \mathrm{g} / \mathrm{mL}$ and $22-110 \mu \mathrm{g} / \mathrm{mL}$ for amentoflavone, quercetin and ginkgetin, respectively were prepared in methanol, giving linear calibration curves $\mathrm{y}=1.4317 \mathrm{x}-49.013$, $\mathrm{R}^{2}=0.9967 ; \mathrm{y}=1.7822 \mathrm{x}-4.2832, \mathrm{R}^{2}=0.9989$ and $\mathrm{y}=1.1579 \mathrm{x}-13.09, \mathrm{R}^{2}=0.9989$ for them, respectively. The extraction yields of amentoflavone, quercetin and ginkgetin were calculated according to the calibration curves, respectively.

\subsection{Experimental Design}

Amentoflavone, quercetin and ginkgetin are classified as flavonoids, which are polar compounds. It is necessary to add small amounts of modifiers for extraction of the polar components in supercritical $\mathrm{CO}_{2}$ extraction [15]. In this work, four factors, i.e., extraction time, temperature, pressure and different concentration of ethanol were studied for their effects on the extraction yield of the three components. A central composite design (CCD) with four variables at five levels was used, which allows the modeling of curvature within the factor space and improving the quality of prediction. Based on the $\mathrm{CCD}$, thirty runs with six replicate in center points were considered [16]. The range of independent variables and their levels is presented in Table 4, which was based on the results of preliminary experiments. The software Design Expert (Stat-Ease Inc., Minneapolis, MN, USA) was employed for experimental design, data analysis, and model building. The matrix for the optimization experiment is summarized in Table 1. In this study, the experimental run was randomized in order to reduce the error arising from the experimental process.

The relationship between the response and the independent variables was calculated by the second-order polynomial equation (Equation (4)). The non-linear computer-generated quadratic model is used for this model:

$$
Y=\beta_{0}+\sum_{i=0}^{4} \beta_{i} x_{i}+\sum_{i=0}^{4} \beta_{i i} X_{i}^{2}+\sum_{i=0}^{4} \sum_{j=1}^{4} \beta_{i j} X_{i} X_{j}
$$

where $\mathrm{Y}$ is the predicted response; $\mathrm{X}_{\mathrm{i}}$ and $\mathrm{X}_{\mathrm{j}}$ are independent variables which influence the response variable $Y ; \beta_{0}$ is the offset term; $\beta_{\mathrm{i}}$ is the ith linear coefficient; $\beta_{\mathrm{ii}}$ is the ith quadratic coefficient; and $\beta_{\mathrm{ij}}$ is the ijth interaction coefficient.

Table 4. Factors and levels studied using CCD.

\begin{tabular}{|c|c|c|c|c|c|c|}
\hline \multirow{2}{*}{ Factors } & \multirow{2}{*}{ Coded Symbols } & \multicolumn{5}{|c|}{ Levels } \\
\hline & & -2 & -1 & $\mathbf{0}$ & 1 & 2 \\
\hline Extraction time $(\mathrm{h})$ & $\mathrm{X}_{1}$ & 1 & 1.5 & 2 & 2.5 & 3 \\
\hline Extraction temperature $\left({ }^{\circ} \mathrm{C}\right)$ & $\mathrm{X}_{2}$ & 35 & 40 & 45 & 50 & 55 \\
\hline Extraction pressure $(\mathrm{MPa})$ & $\mathrm{X}_{3}$ & 10 & 15 & 20 & 25 & 30 \\
\hline $\begin{array}{l}\text { Ethanol concentration } \\
\text { (ethanol/water, v/v, \%) }\end{array}$ & $\mathrm{X}_{4}$ & 60 & 70 & 80 & 90 & 100 \\
\hline
\end{tabular}




\section{Conclusions}

The process parameters of SFE of amentoflavone, quercetin and ginkgetin from the leaves of T. chinensis were successfully optimized by response surface methodology. The optimum parameters for extraction of amentoflavone were $48{ }^{\circ} \mathrm{C}, 25 \mathrm{MPa}, 2.02 \mathrm{~h}$ and $78.5 \%$ ethanol; $46{ }^{\circ} \mathrm{C}, 24 \mathrm{MPa}, 2.3 \mathrm{~h}$, $82 \%$ ethanol and $48{ }^{\circ} \mathrm{C}, 20 \mathrm{MPa}, 2.38 \mathrm{~h}, 82 \%$ ethanol for the extraction of quercetin and ginkgetin, respectively. The maximum yield $(4.47 \mathrm{mg} / \mathrm{g})$ at optimized conditions for amentoflavone extraction $\left(48{ }^{\circ} \mathrm{C}, 25 \mathrm{MPa}, 2 \mathrm{~h}\right.$ and $78 \%$ ethanol) could be obtained with higher yield for extraction of quercetin $(3.65 \mathrm{mg} / \mathrm{g})$ and ginkgetin $(3.39 \mathrm{mg} / \mathrm{g})$, respectively. The optimized parameters for the extraction of the three components are helpful for applications of the plant resource using the environmentally friendly SFE technique. The developed SFE method with UPLC analysis offers a suitable method of quality evaluation for the plant.

\section{Acknowledgments}

The authors are grateful to the Natural Science Foundation of China (NSFC, Project No: 30470330, 30360087, 30770334, 30960313; ZPNSFC, Project No: Y2110691) for the financial support of the work.

\section{Author Contributions}

Qiang Wang designed research; Xiao Ruan, Liu-Ye Yan, Xian-Xian Li, Ben Liu, Huan Zhang and Qiang Wang performed research and analyzed the data; Xiao Ruan, Ben Liu, and Qiang Wang wrote the paper. All authors read and approved the final manuscript.

\section{Conflicts of Interest}

The authors declare no conflict of interest.

\section{References}

1. Rezende, T.P.; Correa, J.O.; Aarestrup, B.J.; Aarestrup, F.M.; de Sousa, O.V.; da Silva Filho, A.A. Protective effects of Baccharis dracunculifolia leaves extract against carbon tetrachloride- and acetaminophen-induced hepatotoxicity in experimental animals. Molecules 2014, 19, 9257-9272.

2. Luo, C.Y.; Wang, X.X.; Gao, G.; Wang, L.; Li, Y.X.; Sun, C.J. Identification and quantification of free, conjugate and total phenolic compounds in leaves of 20 sweetpotato cultivars by HPLC-DAD and HPLC-ESI-MS/MS. Food Chem. 2013, 141, 2697-2706.

3. Guo, N.; Zhu, M.X.; Han, X.J.; Sui, D.; Wang, Y.; Yang, Q. The metabolism of salidroside to its aglycone $p$-tyrosol in rats following the administration of salidroside. PLoS One 2014, 9. doi:10.1371/journal.pone.0103648.

4. Znati, M.; Jannet, B.; Cazaux, S.; Bouajila, J. Chemical composition, biological and cytotoxic activities of plant extracts and compounds isolated from Ferula lutea. Molecules 2014, 19, 2733-2747. 
5. Ragab, F.A.; Yahya, T.; El-Naa, M.M.; Arafa, R.K. Design, synthesis and structure-activity relationship of novel semi-synthetic flavonoids as antiproliferative agents. Eur. J. Med. Chem. 2014, 82, 506-520.

6. Anouar, E.; Shah, S.; Hassan, N.B.; El Moussaoui, N.; Ahmad, R.; Zulkefeli, M.; Weber, J. Antioxidant activity of hispidin oligomers from medicinal fungi: A DFT study. Molecules 2014, 19, 3489-3507.

7. Sun, L.; Simmerling, C.; Ojima, I. Recent advances in the study of the bioactive conformation of taxol. ChemMedChem 2009, 4, 719-731.

8. Wu, M.B.; Wu, Y.L.; Zhou, J.; Pan, Y.J. Structural characterisation of a water-soluble polysaccharide with high branches from the leaves of Taxus chinensis var. mairei. Food Chem. 2009, 113, 1020-1024.

9. Ruan, X.; Zhan, L.M.; Gao, X.X.; Yan, L.Y.; Zhang, H.; Zhu, Z.Y.; Wang, Q.; Jiang, D.A. Separation and purification of flavonoid from Taxus remainder extracts free of taxoids using polystyrene and polyamide resin. J. Sep. Sci. 2013, 36, 1925-1934.

10. Lien, H.M.; Chiu, C.H.; Chen, C.C.; Chang, W.L.; Chyau, C.C.; Peng, R.Y. Comparison of the apoptotic effects of supercritical fluid extracts of Antrodia cinnamomea mycelia on hepatocellular carcinoma cells. Molecules 2014, 19, 9033-9050.

11. Saviano, A.M.; Francisco, F.L.; Lourenco, F.R. Rational development and validation of a new microbiological assay for linezolid and its measurement uncertainty. Talanta 2014, 127, 225-229.

12. Zhang, Y.J.; Mo, L.M.; Chen, F.; Lu, M.Q.; Dong, W.J.; Wang, Q.H.; Xu, F.; Gu, F.L. Optimized production of vanillin from green vanilla pods by enzyme-assisted extraction combined with pre-freezing and thawing. Molecules 2014, 19, 2181-2198.

13. Benelli, P.; Riehl, C.; Smania, A.; Smania, E.; Ferreira, S. Bioactive extracts of orange (Citrus sinensis L. Osbeck) pomace obtained by SFE and low pressure techniques: Mathematical modeling and extract composition. J. Supercrit. Fluids 2010, 55, 132-141.

14. Erkucuk, A.; Akgun, I.H.; Yesil-Celiktas, O. Supercritical $\mathrm{CO}_{2}$ extraction of glycosides from Stevia rebaudiana leaves: Identification and optimization. J. Supercrit. Fluids 2009, 51, 29-35.

15. Herrero, M.; Castro-Puyana, M.; Mendiola, J.A.; Ibanez, E. Compressed fluids for the extraction of bioactive compounds. TrAC Trends Anal. Chem. 2013, 43, 67-83.

16. Liu, X.; Yang, D.L.; Liu, J.J.; Xu, K.; Wu, G.H. Modeling of supercritical fluid extraction of flavonoids from Calycopteris floribunda leaves. Chem. Pap. 2014, 68, 316-323.

Sample Availability: Samples of the compounds are available from the authors.

(C) 2014 by the authors; licensee MDPI, Basel, Switzerland. This article is an open access article distributed under the terms and conditions of the Creative Commons Attribution license (http://creativecommons.org/licenses/by/4.0/). 